\title{
Large optic disc melanocytoma: A rare entity
}

\author{
Priti Singh', Devendra Pratap Singh Rajput ${ }^{2}$, S.B. Gupta ${ }^{3}$, Rashmi Kumar ${ }^{4}$ \\ ${ }^{1}$ Assistant Professor, Dept. of Ophthalmology, L.N.Medical College, Bhopal, ${ }^{2}$ Associate Professor, Dept. of Medicine, L.N.Medical College, \\ Bhopal, ${ }^{3}$ Professor, Dept. of Ophthalmolgy, L.N.Medical College, Bhopal, ${ }^{4}$ Assistant Professor, Dept. of Ophthalmology, L.N.Medical College, \\ Bhopal
}

\section{A B S T R A C T}

Optic disc melanocytoma is a deeply pigmented variant of benign melanocytic nevus that has been confused with malignant melanoma. Optic disc melanocytomas are locally invasive but are not known to undergo transformation into malignant melanoma. We present an unusual case of a melanocytoma of the optic disc that is a coincidental finding on routine fundus examination even though the size of the melanocytoma is quiet large around 2.5 DD $(3.7 \mathrm{~mm}$ ) in size (while usually mean tumour diameter is $2 \mathrm{~mm}$ only) Follow up should remain the primary approach in the management of the patients with optic nerve melanocytomas as they are benign, as previously advocated by Zimmerman.

Key words: Melanocytoma, Nevus, Benign, Malignant

\section{INTRODUCTION}

Melanocytoma of the optic disc is a rare melanotic lesion that occurs in dark skinned individuals. It is typically a stationary, unilateral lesion, possibly more common among women, that virtually never undergoes malignant transformation. ${ }^{1}$

Historically this tumour was confused with malignant melanoma both clinically and histopathologically. Today however it is generally recognized by its typical clinical features that differ from most melanomas and erroneous enucleation is rarely done.

The term melanocytoma was first used by Zimmerman and Garron $^{3}$ to describe a deeply pigmented benign tumour arising from the optic disc. Before this they were considered as peripapillary melanomas invading the optic nerve head. ${ }^{4}$

Subsequently Cogan coined the term" magnocellular nevus " 5 and Reese the term 'benign melanoma' to describe the same lesion. ${ }^{6}$

Visual impairment with melanocytomas can occur from simple enlargement of blind spot to severe visual loss.

\section{CASE REPORT}

The patient was a middle aged female of 48 years who was found to have a optic disc melanocytoma on a routine ophthalmoscopic examination.

The patient was referred to ophthalmology OPD from skin OPD for fundus examination to rule out any macular pathology as they have to start hydroxychloroquin to the patient for severe photodermatitis. As such patient has no ocular complaints on presentation.

On examination, the visual acuity in right eye was $6 / 9 \mathrm{p}$, not improving with pinhole and in left eye visual acuity was $6 / 6$.

Anterior segment of left eye was within normal limits but in the right eye mild RAPD was present. On visual field charting there was slight enlargement of the blind spot.

On fundus examination, a left eye fundus was within normal limits (Figure 1), but in right eye there was a large heavily pigmented lesion of around 2.5 disc diameter over the disc (Figures 2 and 3) which has covered the nasal half of the disc. There was blurring of the remaining disc margins with sheathing of the vessels on and around the disc and over the lesion. There was also another very 


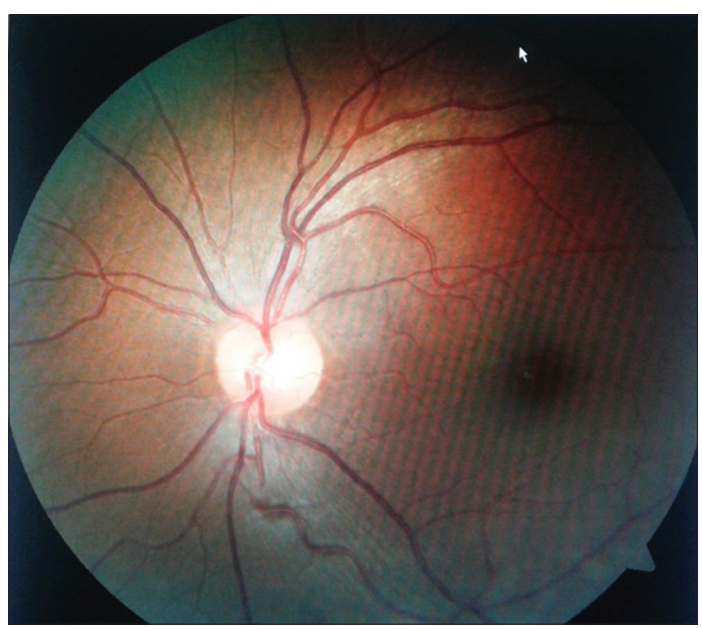

Figure 1: Fundus picture of left eye

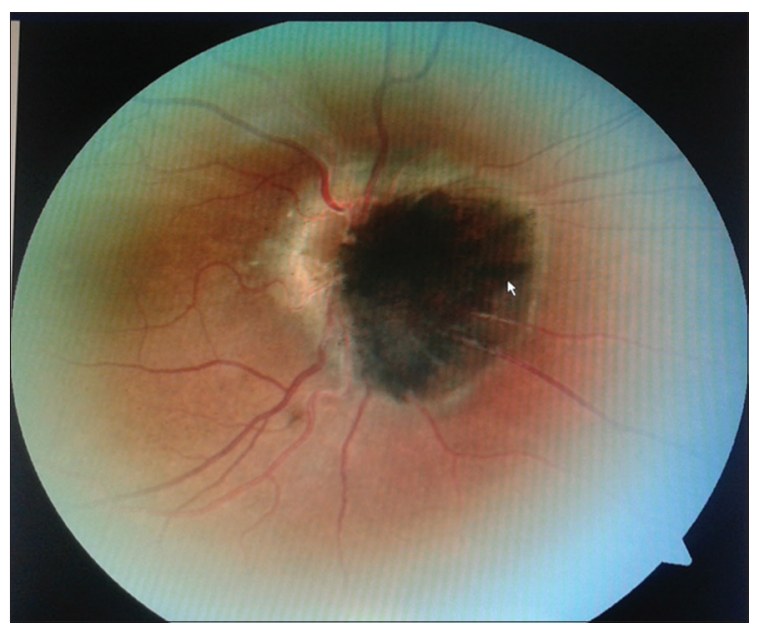

Figure 2: Fundus picture of right eye of the patient showing a large optic disc melanocytoma (around 2.5 DD in size) and a small pigmented lesion inferotemporal to the disc

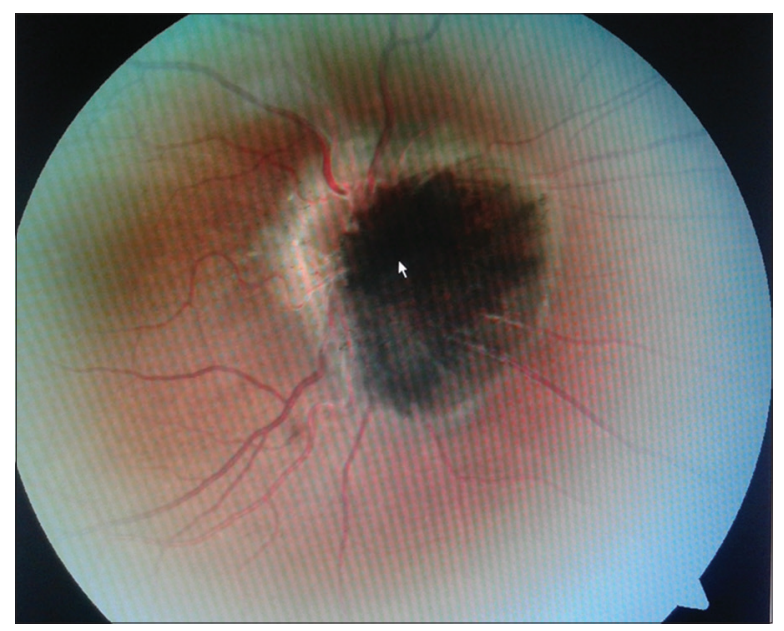

Figure 3: Fundus picture of right eye of the patient showing a large optic disc melanocytoma (around 2.5 DD in size) and a small pigmented lesion inferotemporal to the disc small (around $0.5 \mathrm{~mm}$ diameter size) pigmented lesion inferotemporal to the disc.

Patient was advised fluorosceine angiography but she did not report.

Several features in our case are typical of an optic nerve melanocytoma. They include the jet black colouration, the feathery edges, the origin from the optic disc, the relatively well preserved vision and visual fields.

\section{DISCUSSION}

There was a controversy regarding the origin of these melanotic tumours as to whether they arise within the disc or represent invasion of the nerve head from a juxtapapillary malignant melanoma.

Although some studies have pointed out that the lamina cribrosa of many animal species including on occassion man, contains pigment and is a potential source of pigmented lesions, other have questioned the actual occurrence of melanotic neoplasms primary in nerve head. ${ }^{3}$

Zimmerman established the entity of 'melanocytomas', choosing this term in part to indicate the benign behaviour of the darkly pigmented lesion of the optic disc after doing a large clinical and histopathological study of such lesions with long-term follow-up. ${ }^{3,7-9}$

Although melanocytomas of the optic disc tend to have a benign behaviour with slow evolution and stable vision, they may adversely affect visual function through a variety of mechanism. ${ }^{2}$

Frequently melanocytes are identified coincidently, and visual impairment, apart from an enlarged blind spot where the tumour occupies the optic disc is rare. ${ }^{2}$ However, some have reported severe visual loss also. ${ }^{10}$

Also in certain cases where melanocytomas enlarge rapidly and lead to sudden visual loss and necrosis can be found in the literature. ${ }^{8,10,11}$

The major cause of decreased vision is attributed to the swelling of axons from compression of the nerve fibres and their vascular supply by the tumour. ${ }^{17}$ This explains why deeply seated optic nerve melanocytomas, describe their small apparent size, may result in visual loss. ${ }^{8,9}$

Melanocytomas are usually asymptomatic.A slow impairment of visual acuity attributed to the tumour is reported to occur in approximately $5 \%$ of cases. $^{2}$ 
Cases accompained by significant loss of visual acuity and/or visual field have also been reported. ${ }^{2}$

Rashaed etal in their study found that tumour-related visual impairment was due to macular exudation, optic atrophy from optic nerve compression by the tumour, foveal choroidal neovascularisation, optic disc edema and peripapillary subretinal fluid. ${ }^{2}$

So, although optic disc melanocytomas tend to be benign in behaviour, they may adversely affect visual function.

Melanocytoma, also known as magnocellular nevus, is benign, stationary heavily pigmented tumour that may develop wherever uveal melanocytes are present and most commonly occur on, or adjacent to the optic disc with little potential for growth. ${ }^{2}$

It exhibits remarkably little pigment variation, appearing as a jet-black mass that usually occupies the inferotemoporal quadrant of the disc. ${ }^{1}$

The zone of pigmentation frequently extends into the adjacent retina; the advancing border of the melanocytoma often has a feathery outline. ${ }^{1}$

Melanocytomas of the optic disc typically appear as an elevated dark brown or black lesion, which occupies part or occasionally the entire optic disc. ${ }^{4}$ Melanocytomas usually extend over the edage of the optic disc and in about half the cases appear to have an associated contiguous choroidal naevus ${ }^{12}$ which is merely an extension of the melanocytoma beneath the juxtapapillary retinal pigment epithelium.

The melanocytoma was dark brown to black in $100 \%$ of patients the mean tumour diameter was $2 \mathrm{~mm}$ and the mean thickness was $1 \mathrm{~mm} .{ }^{11}$ Melanocytoma usually do not exceed one disc diameter in size. ${ }^{2}$

Fluoresceine angiography demonstrates a rather characteristic blockage of fluorescence by the tumour. ${ }^{1}$ In fluoresceine angiography, a characteristic blockage of the fluorescence by the tumour is seen. ${ }^{1}$. Fluoresceine angiography can be useful to differentiatee between malignant melanoma and melanocytoma. ${ }^{13}$

In a study of 115 patients (116eyes) with melanocytoma of the optic disc, the mean age at diagnosis was 50years, $38 \%$ of patients were male and $62 \%$ of the patients were female: $65 \%$ of the patients were white, $29 \%$ of patients were African American and 6\% of the patients were Asian, hispanic, Indian or Arabic. ${ }^{11}$ The lesion was unilateral in $99 \%$ of patients. Visual symptoms that seemed to be related to the melanocytoma were present in $24 \%$ of patients and an afferent pupillary defect was noted in $9 \%$ of patients. ${ }^{11}$

Melanocytomas of the optic nerve have been characterised as stable or slowly growing lesions. ${ }^{4}$ Melanocytomas are in fact merely a form of naevus which are characterised clinically by their dark brown or black colouration and histopathlogically by the presence of rather plump, round to oval deeply pigmented cells with small round nuclei which lack significant pleomorphism. ${ }^{4}$

Although benign, optic disc melanocytomas may enlarge in size. Joffe etal evaluated 27 cases of optic disc melanocytoma and an increase In size in four $(15 \%)$ cases. $^{12}$

Apple et $a l^{15}$ described the first case of malignant transformation of an optic nerve melanocytoma. Shields etal recently documented that the rate of malignant transformation is approximatedly $1-2 \%{ }^{16}$

Once the basic pathology of melanocytomas was established, they were considered to have no malignant potential. Subsequent reports have shown that these tumours can, in rare instances, undergo malignant transformation ${ }^{4}$ and for this reason periodic observation of such lesions is mandatory.

\section{REFERENCES}

1. Levine R A, Rosenberg M A, Rabb M F.The Optic Nerve. In: Peyman G A, Sanders D R, Goldberg M F- editors. Principles and practice of ophthalmology.1st ed vol iii. New Delhi: Jaypee and W B Sauders;1987.p.2132-2136.

2. Al-Rashaed S, Abboud E B, and Nowilaty S R. Characteristics of Optic Disc Melanocytomas Presenting with Visual Dysfunction. Middle East Afr J Ophthalmol. 2010 Jul-Sep; 17(3): 242-245.

3. Zimmerman LE, Garron LK. Melanocytoma of the optic disc. Int Ophthalmol Clin. 1962;2:431-40.

4. I G Rennie. Things that go bump in the light. The differential diagnosis of posterior uveal melanomas. Eye 2002; 16: 325-346.

5. Cogan DG. Discussion: Pigmented ocular tumors. In: Boniuk M, ed. Ocular and adnexal tumours: new and controversial aspects. St Louis: Mosby, 1964: 385.

6. Cogan DG. Discussion: Pigmented ocular tumors. In: Boniuk M, ed. Ocular and adnexal tumours: new and controversial. St Louis: Mosby, 1964: 385.

7. Zimmerman LE. Pigmented tumours of the optic nerve head $(22 d$ annual deSchweinitz lecture). Am J Ophthalmol 1960; 50: 338.

8. Zimmerman LE. Melanocytes, melanocytic nevi, and melanocytomas. The Jonas S. Friedenwald Memorial Lecture. Invest Ophthalmol Vis Sci 1965; 4: 11-41.

9. Zimmerman LE. Changing concepts concerning the malignancy of ocular tumours. Arch Ophthalmol 1967; 78: 166-73.

10. Croxatto JO, Ebner R, Crovetto L, Morales AG. Angle closure glaucoma as initial manifestation of melanocytoma of the optic disc. Ophthalmology. 1983;90:830-4.

11. Shields JA, Demirci H, Mashayekhi A, Shields CL. Melanocytoma 
of optic disc in 115 cases: The Samuel Jackson Memorial Lecture, Part 1. Ophthalmology. 2004;111:1739-46.

12. Joffe L, Shields JA, Osher RH, Gass JD. Clinical and follow-up studies of melanocytomas of the optic disc. Ophthalmology 1979; 86: 1067-1083

13. Sharma h, puri Ir. Melanocytoma of the optic disc - a case report. Nepal j ophthalmol. 2012 jul-dec;4(2):323-5.

14. Usui T, Shirakashi M, Kurosawa A, Abe H, Iwata K. Visual disturbance in patients with melanocytoma of the optic disc. Opthalmologica. 1990;201:92-8.
15. Apple DJ, Craythorn JM, Reidy JJ, Steinmetz RL, Brady SE,Bohart WA. Malignant transformation of an optic nerve melanocytoma.Can J Ophthalmol 1984; 19: 320-5.

16. Shukla S Y, shields J A, Eagle C R, Shields C L. Transformation of optic disc melanocytoma into melanoma over 33 years.arch ophthalmol. 2012;130(10):1344-1347.

17. Ahmad M Mansour,' Lorenz Zimmerman,2 Francis G La Piana,3 And George $\mathrm{R}$ Beauchamp. Clinicopathological Findings In A Growing Optic Nerve Melanocytoma. British Journal Of Ophthalmology, 1989, 73, 410-415.

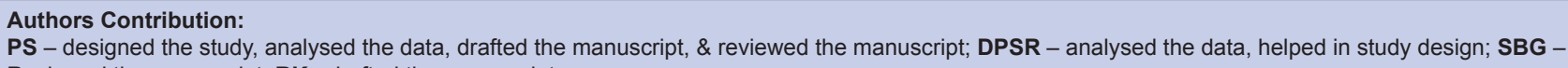

